\title{
O trabalho do assistente social na saúde mental: revisão narrativa
}

\author{
The work of the social worker in mental health: narrative review \\ El trabajo del trabajador social en salud mental: revisión narrativa
}

Adelina Almeida Moreira de Araújo ${ }^{1 *}$.

\begin{abstract}
RESUMO
Objetivo: Discutir, por meio de revisão narrativa da literatura científica, a atuação do Assistente Social na Saúde Mental. Revisão bibliográfica: A partir da Reforma Psiquiátrica em 1978, asilos e hospitais psiquiátricos são substituídos gradualmente por serviços psicossociais abertos e comunitários, com vistas ao atendimento das necessidades individuais dos usuários em sofrimento psíquico utilizando-se de abordagem humanizada. Sendo a violação dos direitos sociais um grande desafio lançado ao Assistente Social demandado pela Saúde Mental, faz-se necessário uma análise sobre o seu fazer profissional nesse espaço de trabalho, seu papel de atuação, entender como se dá o acolhimento no campo da saúde, além de situar a população usuária enquanto sujeitos de direitos, ressaltando a importância da escuta qualificada junto ao serviço social. Considerações finais: As expressões da Questão Social na Saúde Mental são verificadas a partir da exclusão social dos usuários em sofrimento psíquico através da privação de seu convívio social, na falta de inserção nas redes intersetoriais, além da estigmatização que enfrentam diariamente, acarretandoIhes prejuízos sociais e emocionais.
\end{abstract}

Palavras-Chave: Trabalho, Serviço social, Saúde mental.

\begin{abstract}
Objective: Discuss, through a narrative review of the scientific literature, the role of the Social Worker in Mental Health. Bibliographic review: From the Psychiatric Reform in 1978, psychiatric hospitals and asylums are gradually replaced by open and community psychosocial services, with a view to meeting the individual needs of users in psychological distress using them. humanized approach. As the violation of social rights is a great challenge to the Social Worker demanded by Mental Health, it is necessary to analyze his professional practice in this work space, his role in acting, to understand how they are welcomed in the health field, in addition to placing the user population as subjects of rights, emphasizing the importance of qualified listening with the social service. Final Considerations: The expressions of the Social Question in Mental Health are verified from the social exclusion of users in psychological distress through the deprivation of their social life, in the lack of insertion in the intersectoral networks, in addition to the stigmatization they face daily, causing harm to them social and emotional.
\end{abstract}

Key words: Work, Social work, Mental health.

\section{RESUMEN}

Objetivo: Discutir, a través de una revisión narrativa de la literatura científica, el papel del trabajador social en la salud mental. Revisión bibliográfica: La Reforma psiquiátrica de 1978, los hospitales psiquiátricos y los asilos se reemplazan gradualmente por servicios psicosociales abiertos y comunitarios, con el fin de satisfacer las necesidades individuales de los usuarios con problemas psicológicos que los utilizan. Enfoque humanizado. Como la violación de los derechos sociales es un gran desafío para el trabajador social exigido por la salud mental, es necesario analizar su práctica profesional en este espacio de trabajo, su papel en la actuación, para comprender cómo son bienvenidos en el campo de la salud, además de ubicar a la población de usuarios como sujetos de derechos, enfatizando la importancia de la escucha calificada con el servicio social. Consideraciones finales: Las expresiones de la Cuestión social en salud mental se verifican a partir de la exclusión social de los usuarios con problemas psicológicos a través de la privación de su vida social, la falta de inserción en las redes intersectoriales, además de la estigmatización que enfrentan a diario, causándoles daño. social y emocional.

Palabras clave: Trabajo, Trabajo social, Salud mental.

${ }^{1}$ Universidade Católica de Brasília (UCB), Brasília - DF. *E-mail: adelina.araujo@p.ucb.br

SUBMETIDO EM: 5/2020

ACEITO EM: 6/2020

PUBLICADO EM: 9/2020 


\section{INTRODUÇÃO}

Conforme Amarante P e Nunes MO (2018), a partir da Reforma Psiquiátrica em 1978, asilos e hospitais psiquiátricos são substituídos gradualmente por serviços psicossociais abertos e comunitários, com vistas ao atendimento das necessidades individuais dos usuários em sofrimento psíquico utilizando-se de abordagem humanizada. Iniciava-se então um período de reflexões sobre a maneira como a "loucura" era vista pela sociedade pois a assistência ainda estava situada nas internações psiquiátricas e na negação dos direitos da pessoa em sofrimento psíquico sobre o processo saúde-doença.

No decorrer dos anos de 1980, a Reforma Psiquiátrica conferiu ao Estado o direcionamento da Política de Saúde Mental pontuando três direções principais: o gerenciamento e controle geral do sistema, principalmente das internações fáceis e do processo de mercantilização da assistência na rede de hospitais conveniados; a reflexão crítica e "humanização" da realidade interna dos asilos e hospitais, com eliminação das formas mais severas de controle dos pacientes e ensaios de programas de reabilitação social, principalmente via oficinas expressivas e atividades laborativas e processos de desospitalização (ARGILES CT, et al., 2013).

As primeiras reformas, implementadas em algumas tiveram um papel crucial no desenvolvimento de um modelo adaptado às especificidades do contexto brasileiro e deram contribuições valiosas para os primeiros passos na construção de uma política nacional de saúde mental. Essa política viria, no decurso dos anos 1980, a integrar-se ao processo de redemocratização iniciado nesse período no Brasil e a ganhar forças nas esferas legislativas, administrativas e financeiras.

De acordo com Vasconcelos, EM (2000), deu-se ainda a criação de equipes de saúde mental (psiquiatra, psicólogo e assistente social) em ambulatórios e postos de saúde, com regionalização das ações para uma atenção primária e preventiva em saúde mental, dentro do que foi chamado de Ações Integrais de Saúde (AIS), esboço do que constituiu mais tarde o Sistema Único de Saúde (SUS). A partir desta mudança, era preciso adequar esse processo de trabalho na lógica da ação territorial, ação grupal e no trabalho em equipe, atuando então de forma multiprofissional e interdisciplinar, para que o usuário pudesse ser visto nas suas maiores dimensões, e não apenas sob a ótica médica, da enfermidade e dos sintomas (MELO AMC ,2012).

Foi em 1988, com a Constituição Federal, que se consolidou os resultados das mobilizações sociais com objetivos da ampliação de acesso aos direitos, bem como o processo de democratização, efetuado pelo tripé da Seguridade Social no Brasil, Saúde, Previdência Social, e Assistência Social, na garantia dos direitos fundamentais (TAVARES CMM, et al., 2014).

A proposta do SUS veio ancorada numa concepção ampliada de saúde e hoje se discute que as ações profissionais se viabilizem especialmente através do marco conceitual da promoção da saúde e de pautas programáticas expressas pelo Ministério da Saúde. Antes do advento do SUS, a atuação do Ministério da Saúde se resumia às atividades de promoção de saúde e prevenção de doenças, e à assistência médicohospitalar; servia aos indigentes, ou seja, a quem não tinha acesso ao atendimento pelo Instituto Nacional de Assistência Médica da Previdência Social (INAMPS).

A partir da descentralização do Estado, a relação do Serviço Social com a Reforma psiquiátrica marca os movimentos democratizantes a partir da Constituição Federal de 1988, preconizados sob o olhar à pessoa em sofrimento psíquico, fez-se o pensar da profissão em uma nova conceituação, inaugurando um novo modelo de atenção, não somente em diagnóstico científico patológico da medicina, mas com um olhar voltado ao sujeito, utilizando-se o termo reabilitação psicossocial (HERNANDES KM, et al., 2011).

A construção de um modelo de atenção descentralizado, no qual o manicômio não é o dispositivo central da rede de serviços, demanda cada vez mais a necessidade de profissionais comprometidos com os princípios da reforma psiquiátrica brasileira, potencialmente capazes de contribuir para a materialização da política de saúde mental. Portanto, importa-nos que a reforma da psiquiatria significou a problematização social de saberes até então cristalizados, avançando na direção de reconhecimento da reabilitação social do indivíduo, promovendo uma atenção à saúde integralizada à seguridade social, buscando a efetivação da cidadania do doente mental e instrumentalizar a atenção psicossocial a este segmento (AZEVEDO DM e SANTOS AT, 2012). 
O movimento psiquiátrico se aproxima dos objetivos na reorganização das políticas públicas sociais junto do Processo de Reconceituação do Serviço Social caminhando num sentido único, no período dos anos de 1990, no que diz respeito para a profissão de Assistente Social, um deslocamento para linha marxiana, em oposto dos ideais do profissional tradicional, materializando-se na construção do Projeto Ético-Político da profissão dos meados anos de 1970 e 1980 (FALEIROS VCP, 2011).

Ainda, neste mesmo ano, de 1990, com os movimentos de lutas pela mobilização da promulgação de Lei do Sistema Único de Saúde, ㄲo 8080/1990, ou seja, a Lei Orgânica da Saúde (LOS), que detalha seus objetivos, diretrizes e competência a cada esfera de governo tanto, Federal, Estadual e Municipal, atribuindo os princípios da universalidade, da equidade e da integralidade, é sancionada também a Lei oㅡ 8.142/90 que trata da participação da população na gestão do SUS (BRASIL, 2013).

A partir dos anos 90, com a implementação do SUS, mudanças de ordens tecnológica, organizacional e política passaram a exigir novas formas de organização do trabalho na saúde, determinadas pela hierarquização por nível de complexidade, descentralização e democratização do sistema, imprimiram novas características ao modelo de gestão e atenção e, portanto aos processos de trabalho.

A atual organização do sistema de saúde, ao tempo em que atende algumas reivindicações históricas do movimento sanitário, de que são exemplos a universalização, a descentralização e a incorporação dos mecanismos. Portanto, o presente trabalho tem por objetivo discutir a atuação do Assistente Social na Saúde Mental.

\section{REVISÃO BIBLIOGRÁFICA}

A trajetória do Serviço Social na área da saúde no contexto brasileiro se dá a partir de 1920. Tal década é marcada pelo discurso do poder, com tentativas de extensão dos seus serviços por todo o país. Como exemplo, a Reforma Carlos Chagas de 1923, tenta ampliar o atendimento à saúde por parte do poder central, constituindo uma das estratégias da União de ampliação do poder nacional no interior da crise política em curso, sinalizada pelos tenentes, a partir de 1922 (BRAVO MIS, 2007).

Já a conjuntura de 30 a 45 caracteriza o surgimento da profissão no Brasil, com influência europeia, e a área da saúde não foi a que concentrou maior quantitativo de profissionais, apesar de algumas escolas terem surgido motivadas por demandas do setor. A formação profissional também se pautou, desde seu início, em algumas disciplinas relacionadas à saúde. O surgimento e o desenvolvimento do Serviço Social no período de 30 a 64, bem como a ação profissional na área da saúde, mostram algumas evidências significativas (BRAVO MIS, 2007).

A política de saúde formulada nesse período era de caráter nacional, organizada em dois subsetores: o de saúde pública e o de medicina previdenciária. O subsetor de saúde pública será predominante até meados de 60 e se centralizará na criação de condições sanitárias mínimas para as 18 populações urbanas e, restritamente, para as do campo. O subsetor de medicina previdenciária só virá sobrepujar o de saúde pública a partir de 1966.

A expansão do Serviço Social no país, entretanto, ocorre a partir de 1945, relacionada com as exigências e necessidades de aprofundamento do capitalismo no Brasil e às mudanças que ocorreram no panorama internacional, em função do término da $2^{a}$ Guerra Mundial. Nesta década, a ação profissional na saúde também se amplia, transformando-se no setor que mais vem absorvendo os Assistentes Sociais. A situação da Saúde no período de 1945 a 1964, não conseguiu eliminar o quadro de doenças infecciosas e parasitárias e as elevadas taxas de morbidade e mortalidade infantil, como também a mortalidade geral (AZEVEDO DM e SANTOS AT, 2012).

O Assistente Social consolidou uma tarefa educativa com intervenção normativa no modo de vida do usuário com relação aos hábitos de higiene e saúde, e atuou nos programas prioritários estabelecidos pelas normatizações da política de saúde. O Serviço Social na saúde vai receber as influências da modernização que se operou no âmbito das políticas sociais, sedimentando sua ação na prática curativa, principalmente na assistência médica previdenciária, maior empregador dos profissionais (BRAVO MIS, 2007). 
O Serviço Social sofreu profundas transformações, no pós-1964, que tiveram rebatimento no trabalho do Assistente Social na área da saúde. No período de 1964 a 1974, o Estado utilizou para sua intervenção o binômio repressão-assistência, sendo a política assistencial ampliada, burocratizada e modernizada pela máquina estatal com a finalidade de aumentar o poder de regulação sobre a sociedade, suavizar as tensões sociais e conseguir legitimidade para o regime, como também servir de mecanismo de acumulação do capital (SILVA MGD, 2007).

Já entre as décadas de 1974 a 1979, o Serviço Social na saúde não se alterou, apesar do processo organizativo da categoria, do aparecimento de outras direções para a profissão, do aprofundamento teórico dos docentes e do movimento mais geral da sociedade. A política Social, no período de 1974 a 1979 teve por objetivo obter maior efetividade no enfrentamento da questão social, a fim de canalizar as reivindicações e pressões populares.

A década de 80 , no Brasil, foi um período de grande mobilização política, como também de aprofundamento da crise econômica que se evidenciou na ditadura militar. Nessa conjuntura, há um movimento significativo na saúde coletiva, que também ocorre no Serviço Social, de ampliação do debate teórico e a incorporação de algumas temáticas como o Estado e as políticas sociais fundamentadas no marxismo (SILVA MGD,2007).

Já na década de 90 é caracterizado por avanços construídos por um conjunto de profissionais situados na tendência de ruptura com o conservadorismo, tanto no aspecto político, como no institucional e no acadêmico. O trabalho do Assistente Social na saúde deve ter como eixo central a busca criativa e incessante da incorporação dos conhecimentos e das novas requisições à profissão, articulados aos princípios dos projetos da reforma sanitária e ético-político do Serviço Social (MATOS MCD,2003).

Feito um pouco desse resgate histórico do Serviço Social na Saúde, ressaltamos que atualmente o trabalho do Assistente Social precisa ser pensado sob a égide da ação territorial, grupal e no trabalho em equipe, com atuação de maneira multiprofissional e interdisciplinar, onde o usuário possa enxergar-se nas mais variadas dimensões, que ultrapassam o olhar sintomático e enfermo (FALEIROS VCP,2011).

O trabalho do Assistente Social na saúde deve ter como eixo central a busca criativa e incessante da incorporação dos conhecimentos e das novas requisições à profissão, articulados aos princípios dos projetos da reforma sanitária e ético-político do Serviço Social (BRAVO MIS, 2007).

O processo de trabalho do Assistente Social também introduz ações para estabelecer parcerias, vínculos e redes de apoio, fortalecendo e ampliando os canais de acesso aos direitos. O resgate da participação do indivíduo e dos grupos na vida social ou na vida organizacional é característica presente em todas as etapas do processo, tornando-se, pois, extremamente importante para a capacitação, a autonomia e a realização dos objetivos (SILVA MGD,2007).

É necessária a atuação de profissionais comprometidos com os princípios da reforma psiquiátrica brasileira com o anseio de contribuir para a solidificação da política de saúde mental. Nesse sentido, ressaltamos que a reforma psiquiátrica significou a problematização social de saberes, prosseguindo na direção do reconhecimento da reabilitação social do indivíduo, promovendo uma atenção à saúde integralizada à seguridade social, na busca pela efetivação da cidadania do indivíduo em sofrimento psíquico (HIRDES AA, 2009).

O Assistente Social munido de seu instrumental técnico-operativo e arsenal teórico-metodológico, no cotidiano de seu trabalho, necessita informa-se rotineiramente sobre a situação do tratamento dos usuários em seu Plano Terapêutico Singular (PTS), além de prestar orientações e apoio sempre que solicitado, destacando a realidade social em que se insere o usuário. Para tanto, muitos são os desafios do Assistente Social ao tentar realizar uma prática intersetorial nas instituições no sentido de buscar estratégias e recorrência às redes externas aqueles que delas necessitarem (MATTOSO FAA, 2009).

Os Assistentes Sociais, com atuação determinada nas principais diretrizes da intersetorialidade; da interdisciplinaridade de atuação em equipe; de cooperação de ensino e atenção entre os profissionais que atuam no campo da Saúde Mental, trocam informações e saberes; de gestão, no viés de coordenação de 
instrumentos de trabalhos precários, sem o subsídio suficiente para dar suporte ao melhor atendimento para com os usuários; de controle social e o processo contemporâneo de desinstitucionalização, com um viés mais humanizado, desfocado na patologia dos usuários (VASCONCELOS EM,2000).

O Serviço Social deve articular e atribuir seu papel de atuação nas dimensões teórico-metodológica, éticopolítica e técnico-operativa no campo da Saúde Mental. Destacamos o trabalho com famílias e o cuidado contínuo com os usuários, identificando seu perfil sócio-econômico, além do trabalho com comunidades, averiguando seus vínculos, culturas locais, lideranças e equipamentos comunitários, relações de vizinhança, intervenções no imaginário social sobre a loucura, dentre outros (VASCONCELOS EM,2000).

Um dos instrumentos utilizados pelos Assistentes Sociais nas Instituições de Saúde Mental é o acolhimento, que tem por objetivo compreender as condições sócio-históricas do usuário em sua totalidade, além de suas demandas. (RIBEIRO RS,2008). Nesse sentido, atuará junto a famílias e comunidades no sentido de contemplar o contexto sócio econômico, sócio familiar, cultural e demográfico. Para tanto, também se utilizará de observação, estudos sociais, parecer social e reuniões com equipe multi e interdisciplinar, dentre outras técnicas e instrumentos (RIBEIRO LA et al, 2014).

De acordo com o Ministério da Saúde (2008), o acolhimento é a recepção do usuário desde sua chegada. Através dele, o profissional ouvirá sua queixa, suas preocupações e angústias. Segundo Wünsch,DM e Morais TC (2013) o acolhimento também se traduz como relação humanizada e acolhedora também entre equipe, ressaltando a importância do trabalho em rede para a garantia dos direitos.

Para Chupel PC e Mioto RCT (2010) o acolhimento no campo da saúde deve ser entendido, ao mesmo tempo, como diretriz ético-estética/política constitutiva dos modos de se produzir saúde e ferramenta tecnológica de intervenção na qualificação de escuta, construção de vínculo, garantia do acesso com responsabilização e resolutividade nos serviços.

O acolhimento como ação técnico-assistencial possibilita que se analise o processo de trabalho em saúde com foco nas relações e pressupõe a mudança da relação profissional/usuário e sua rede social mediante parâmetros técnicos, éticos, humanitários e de solidariedade, trazendo a perspectiva do usuário enquanto sujeito de direitos e que deve participar ativamente no processo de produção da saúde (MATOS MCD,2003).

Reforçando Chupel PC e Mioto RCT (2015) o acolhimento não se trata de um espaço físico, mas uma postura ética: não pressupõe hora ou profissional específico para fazê-lo, implica compartilhamento de saberes, angústias e invenções, tomando para si a responsabilidade de abrigar e agasalhar outrem em suas demandas, com responsabilidade e resolutividade sinalizada pelo caso em questão. Desse modo é que o diferenciamos da triagem, já que não se constitui como uma etapa do processo, mas como ação que precisa acontecer no decorrer do serviço de saúde mental. Por isso ressaltamos que o acolhimento se concretiza no cotidiano das práticas, por meio da escuta qualificada e da capacidade de se pactuar demanda e resposta ao usuário. $O$ que não se pode responder de imediato, pode ser pesquisado e encaminhado com ética e assertividade para garantir $\mathrm{o}$ acesso aos direitos.

Os sujeitos com os quais atua o Assistente Social no cotidiano da assistência à saúde vivenciam um processo de fragilização causado pelo impacto do adoecimento. Em sua maioria, possuem uma trajetória de vida profundamente marcada pela discriminação, desqualificação e exclusão. Neste sentido, acolher estes sujeitos significa compreender a essencialidade da condição de estar doente, dando a eles centralidade, retirando assim o foco da doença. (VASCONCELOS EM,2000). Nesse sentido, existe um compromisso éticopolítico que deve retirar do Assistente Social o papel de um mero executor de tarefas, mas conferir-lhe o estatuto um profissional sensível e corresponsável pela realidade do outro que vai além de orientar e encaminhar demandas, mas que se soma ao sujeito e é capaz de construir e estabelecer processos de isonomia no acesso aos direitos (LACERDA LEP,2014).

Chupel PC e Mioto RCT (2015) apontam que no bojo da intervenção e atuação profissional, a prática de ouvir ganha destaque na medida em que a escuta realizada de forma qualificada proporciona ao Assistente Social a interpretação da realidade a ele apresentada de forma crítica e reflexiva e que na maioria das vezes é a solução dos muitos problemas encontrados por esses usuários através da escuta qualificada, para que a maioria desses usuários possa falar de suas angústias, medos, anseios e dúvidas. 
No Aurélio da Língua Portuguesa, escutar significa tornar-se ou estar atento para ouvir; dar ouvidos a; aplicar o ouvido com atenção para perceber ou ouvir; exercer ou aplicar o sentido da audição. Escutar não é apenas ficar em silêncio. Escutar é colocar um vigoroso interesse no que está sendo ouvido (MATOS $M C D, 2003)$.

Conforme Cadete MMM e Raimundo JS (2012) escutar sugere um esforço duplo: apreender o sentido literário das palavras e procurar entender suas finalidades. A escuta é verificada a partir da construção da nossa subjetividade num determinado contexto. A escuta, denominada a princípio qualificada, deve constituirse então de maneira ampliada, no sentido de ressignificar o sofrimento e de conferir espaço para a construção de um novo olhar sobre as demandas postas pelos usuários.

A escuta revela-se como um processo mental mais sofisticado que o ouvir, trazendo clareza ao objeto de trabalho do Assistente Social, além da reflexão sobre a importância do silêncio sensível à demanda alheia. Para Carvalho CE e Mesquita AC (2014) é pela escuta que se conectam discurso e compreensão e por isso é tão importante que o profissional do Serviço Social possa desenvolver essa escuta qualificada para que consiga apreender as dificuldades e demandas trazidas pelo usuário.

\section{CONSIDERAÇÕES FINAIS}

Ao discutirmos a atuação do Assistente Social na Saúde Mental, concluímos que as expressões da Questão Social nesse âmbito são verificadas a partir da exclusão social dos usuários em sofrimento psíquico, da privação de seu convívio social, na falta de inserção nas redes intersetoriais, além da estigmatização que enfrentam diariamente, acarretando-lhes prejuízos sociais e emocionais. Portanto, um dos maiores desafios postos ao Assistente Social é comprometer-se com o desenvolvimento e aprimoramento de sua capacidade crítica e reflexiva para atuar de forma ética e política frente a realidade dos usuários, construindo assim, estratégias permanentes voltadas à efetivação dos direitos.

\section{REFERÊNCIAS}

1. AMARANTE $P$, NUNES MO. A reforma psiquiátrica no SUS e a luta por uma sociedade sem manicômios. Ciência \& Saúde Coletiva. 2018; 23(6) :2067-2074.

2. ARGILES CT, et al. Redes de sociabilidade: construção a partir do serviço de residência terapêutico. Ciência e Saúde Coletiva, 2013; 18(7), 2049-2058.

3. AZEVEDO DM, SANTOS AT. Ações de saúde mental na atenção básica: conhecimento de enfermeiros sobre a reforma psiquiátrica. Revista de Pesquisa: Cuidado é Fundamental (online), 2012; 4(4), 3006-3014.

4. BRASIL. Sistema Único de Saúde (SUS): princípios e conquistas. Brasília: Ministério da Saúde, 2008.

5. BRASIL. Caderno de Atenção Básica: Saúde mental. Brasília: Ministério da Saúde, 2013.

6. BRAVO MIS. Serviço Social e reforma sanitária: lutas sociais e práticas profissionais. São Paulo: Cortez, 2007.

7. CARVALHO EC, MESQUITA AC. A Escuta Terapêutica como estratégia de intervenção em saúde: uma revisão integrativa. Rev Esc Enferm USP. São Paulo, 2014: online.

8. CHUPEL PC, MIOTO RGT. Acolhimento e serviço social: contribuição para a discussão das ações profissionais no campo da saúde. Revista Serviço Social \& Saúde. Campinas, 2010; 9 (10), 37-54.

9. CHUPEL PC, MIOTO RGT. Acolhimento e Serviço Social: contribuições para o aprimoramento conceitual e interventivo. Revista Intervenção Social. Lisboa, 2015:46(2), 25-40.

10. FALEIROS VP. Estratégias em Serviço Social. São Paulo: Cortez, 2011,208p.

11. HERNANDES KM, et al. Oficina na Atenção Psicossocial: Experimentações com a palavra. Revista de Psicologia da UNESP. 2011; 10(1): 89-99.

12. HIRDES AA. Reforma Psiquiátrica no Brasil: Uma (re)visão. Revista Ciência e Saúde Coletiva. Rio de Janeiro, 2009, 14(1), 297-305.

13. LACERDA LEP. Exercício profissional do assistente social: da imediaticidade às possibilidades históricas. Revista Serviço Social e Sociedade. São Paulo. 2014; 117: 22-44.

14. MATOS MCD. O debate do Serviço Social na saúde nos anos 90. Revista Serviço Social e Sociedade. São Paulo. 2003; (10) 8: 88-110.

15. MATTOSO FAA. Dimensão territorial no trabalho do assistente social na estratégia saúde da família. Revista Em Pauta. 2009; 6 (24) 108-111.

16. MELO AMC. Apontamentos sobre a reforma psiquiátrica no brasil. Cadernos Brasileiros de Saúde Mental. Florianópolis. 2012; 8(9): 84-95.

17. RAIMUNDO JS, CADETE MMM. Escuta qualificada e gestão social entre os profissionais de saúde. Revista Acta Paul Enferm. 2012;25(2):61-70

18. RIBEIRO RS. O trabalho do assistente social e sua inserção no processo de trabalho em saúde: um olhar sobre a atenção primária e a estratégia saúde da família. Revista Libertas, Juiz de Fora. 2008; 8 (1): 91-109. 
19. RIBEIRO LA, et al. Atividades Grupais em Saúde Mental. Revista Baiana de Enfermagem. $2014 ; 28$ (3): $67-69$.

20. SILVA MGD. Processo de Trabalho e Serviço Social. Revista Interações Cultura e Comunidade. Minas Gerais. 2007; 2 (2): 68-85.

21. TAVARES CMM, et al. Cuidado no hospital sob a ótica da equipe de enfermagem. Revista Rene, 2014,15(2), 282290.

22. VASCONCELOS EM. O movimento de higiene mental e a emergência do Serviço Social no Brasil e no Rio de Janeiro. Serviço Social e Sociedade. São Paulo: Cortez, 2000.

23. WÜNSCH DM, MORAIS TC. Textos \& Contextos. Porto Alegre. 2013; 12 (1): 100 - 113. 